\title{
Percepção sonora e conforto acústico em espaços urbanos do município de Belo Horizonte, MG
}

\author{
Sound perception and acoustic comfort in urban spaces in \\ the city of Belo Horizonte, MG
}

\section{Simone Queiroz da Silveira Hirashima Eleonora Sad de Assis}

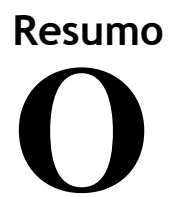

presente artigo tem como objetivo apresentar e analisar as respostas dos usuários de espaços urbanos abertos com relação à percepção do volume sonoro e à avaliação de conforto acústico, com base em dados coletados em campo durante o ano de 2013, em duas praças do município de Belo Horizonte, MG. Durante os levantamentos, dados acústicos foram medidos simultaneamente à aplicação de questionários, utilizados para coleta de variáveis subjetivas e individuais. O LAeq,T foi o índice utilizado para caracterização dos ambientes sonoros. Os resultados demonstram que, sob as mesmas condições acústicas, tanto no que diz respeito à percepção do volume sonoro quanto à avaliação de conforto acústico, os indivíduos tendem a ser mais tolerantes na praça que possui a melhor ambiência e as melhores condições de conforto térmico. As faixas de percepção do volume sonoro definidas neste estudo foram: Baixo, LAeq < $35 \mathrm{~dB}(\mathrm{~A})$; Normal, 36 < LAeq < $67 \mathrm{~dB}(\mathrm{~A})$; Alto, LAeq > $68 \mathrm{~dB}(\mathrm{~A})$. Com relação à avaliação do conforto acústico, as faixas definidas foram: Confortável, LAeq < 67 dB(A); e Desconfortável, LAeq > 68 dB(A). Espera-se que esses resultados contribuam para um maior entendimento das questões relativas ao conforto acústico urbano.

Palavras-chaves: Conforto acústico urbano. Percepção do volume sonoro. Paisagem sonora.

\begin{abstract}
This aim of this paper is to present and analyse the responses of users of urban open spaces regarding perception of loudness and acoustic comfort evaluation, based on data collected during the year of 2013 in two squares in the city of Belo Horizonte, state of Minas Gerais, Brazil. During field surveys, acoustic data were measured simultaneously with the application of questionnaires, which were used to collect subjective and individual variables. The LAeq, T index was used for the characterisation of the acoustic environment. The results show that, under the same acoustic conditions, regarding both the perception of loudness and the evaluation of acoustic comfort, individuals tend to be more tolerant in the square where the ambience and the thermal comfort conditions were better. As for the perception of loudness, the ranges defined in this study were: Low LAeq $<35 \mathrm{~dB}$ (A); Normal $36<$ LAeq < 67dB (A); High LAeq > $68 d B(A)$. Regarding the evaluation of acoustic comfort, the ranges established were: Comfortable, LAeq $<$ $67 \mathrm{~dB}(A)$; and Uncomfortable, LAeq > $68 \mathrm{~dB}(\mathrm{~A})$. We hope that these results will contribute to a better understanding of the issues related to acoustic comfort in urban spaces.
\end{abstract}

Keywords: Soil-cement. Superplasticizer additives. Consistency. Mechanical strength. Shrinkage. Cracking. 


\section{Introdução}

No projeto de um adequado ambiente acústico urbano devem ser considerados não apenas os aspectos físicos do som, mas também aspectos sociais, psicológicos e fisiológicos (KANG; YANG; ZHANG, 2004), uma vez que o conforto acústico não depende unicamente dos níveis sonoros medidos, considerados objetivamente, mas também de variáveis subjetivas (relacionadas aos aspectos psicológicos e fisiológicos) e do contexto social e cultural em que ocorrem.

O estudo do conforto acústico lida, assim, com a subjetividade inerente à percepção, às preferências e à avaliação humana. A percepção humana, que não é uma função linear com relação aos estímulos do ambiente, apresenta dimensões intra $\mathrm{e}$ interpessoal, resultando em uma multiplicidade de respostas ao mesmo estímulo. Além disso, a percepção humana é multissensorial, não ocorrendo isoladamente, mas sim dentro de um contexto global, que inclui, além da informação auditiva, informações sobre outras modalidades sensoriais, como a visão e o tato. Em conjunto, essas várias fontes de informação dão origem a uma representação mental do ambiente percebido e qualquer julgamento será baseado nessa representação multissensorial (VIOLLON; LAVANDIER; DRAKE, 2002). Sendo assim, a avaliação de um local urbano depende da maneira como este responde às necessidades múltiplas, tais como funcionalidade, estética e conforto global (acústica, iluminação, térmica e ventilação) (RAIMBAULT; LAVANDIER; BÉRENGIER, 2003). A maneira como o indivíduo vai perceber $\mathrm{e}$ interpretar as sensações está ainda diretamente ligada às representações individuais e coletivas relacionadas a todos esses fatores ambientais aos quais esse indivíduo está exposto além do som, tais como as condições climáticas, a paisagem visual, a morfologia do ambiente, as práticas nele desenvolvidas, entre outros (PEREIRA, 2003). Múltiplas condições ocorrem simultaneamente, o que mostra a situação de intersensorialidade que caracteriza a relação entre usuário e ambiente (THIBAUD et al., $1998^{1}$ apud PEREIRA, 2003). Por essa razão, Kang, Yang e Zhang (2004) ressaltam que a interação entre o conforto acústico e outros fatores como o conforto visual e o térmico também precisam ser considerados na avaliação dos ambientes.

Ao analisar as relações existentes entre percepção do volume sonoro e conforto acústico, Yang e Kang (2005) demonstram que a regressão da avaliação dos níveis sonoros (percepção do volume

${ }^{1}$ THIBAUD, J.-P. et al. "L'observation des Ambiances" in L'espace Public en Méthode. Grenoble: CRESSON, 1998. sonoro) é quase linear, enquanto a da avaliação do conforto acústico é curva. Assim, quando o nível sonoro é inferior a certo valor, $70 \mathrm{~dB}(\mathrm{~A})$, com o aumento do nível de pressão sonora equivalente contínuo, ponderado na curva A - LAeq, não há mudanças significativas na avaliação de conforto acústico, enquanto a avaliação dos níveis sonoros muda continuamente. Esses autores ressaltam que, nos espaços abertos públicos urbanos, a avaliação das pessoas com relação às mudanças nos níveis sonoros correspondem às mudanças nos níveis sonoros medidos, enquanto a avaliação do conforto acústico é muito mais complexa. As pessoas tendem a ser mais tolerantes com relação à avaliação do conforto acústico, talvez porque esse é determinado por muitos outros fatores além dos níveis sonoros (YANG; KANG, 2005).

As respostas aos mesmos níveis sonoros diferem entre as diferentes populações, com diferentes contextos culturais. Ao se comparar a resposta ao incômodo causado pelo ruído de tráfego, pessoas do Vietnã são menos incomodadas do que os europeus (aproximadamente $5 \mathrm{~dB}$ de diferença) (PHAN e. al., 2010). Nos estudos de Jonsson et al. (1969 ${ }^{2}$ apud LAMURE, 1975) foi demonstrado que as diferenças culturais desempenharam um importante papel, sendo os italianos menos incomodados do que os suecos, embora sujeitos a níveis mais elevados de ruído. Da mesma forma, segundo Saadu et al. (1996), em geral o ruído interfere no mesmo tipo de atividades humanas tanto na Nigéria como na Europa ou nos EUA, mas comparativamente mais baixos percentuais de pessoas são perturbados na Nigéria. Sato et al. $\left(2000^{3}\right.$ apud PHAN et al., 2010) encontraram diferença na resposta ao ruído do tráfego rodoviário entre japoneses e suecos, devido à diferença de estilos de vida no Japão e na Suécia. Em uma pesquisa psicoacústica transcultural, sobre os efeitos da buzina no incômodo realizada no Vietnã e no Japão, uma diferença sistemática foi encontrada entre a resposta dos indivíduos vietnamitas e japoneses. Os japoneses ficavam muito mais incomodados pelo ruído do tráfego rodoviário do que os indivíduos vietnamitas. Os autores especulam que a principal diferença foi causada por diferenças culturais em termos de condições sociais e adaptações ao ruído do tráfego

\footnotetext{
${ }^{2}$ JONSSON, R. E. et al. Annoyance Reactions to Traffic Noise in Italy And Sweden. Archives of Environmental Health, v. 19, p. 692-699, 1969.

${ }^{3}$ SATO, T. et al. Comparison of Community Response to Road Traffic Noise in Sweden, Japan and Thailand. In: WESTERN PACIFIC REGIONAL ACOUSTICS CONFERENCE, 7., Kumamoto, 2000. Proceedings... Kumamoto, 2000
} 
rodoviário em cada país (PHAN et al., $2009^{4}$ apud PHAN et al., 2010).

Tendo em vista sua negativa influência sobre a saúde e a qualidade de vida da população, o ruído, assim considerado o som indesejável, ou o som inútil e sem informação relevante (FUCHS, 1975), começou a ser contemplado recentemente nos projetos urbanos. Porém, o controle do ruído ambiental tem sido prejudicado por um conhecimento insuficiente de seus efeitos e de relações dose-resposta, bem como pela falta de critérios definidos (WORLD..., 1999). Informações disponíveis sobre sons urbanos do cotidiano são raras. Supõe-se geralmente que os ruídos são negativamente interpretados como incômodos ou como poluição inerente às cidades, mas os critérios de conforto acústico para ambientes urbanos não foram determinados (RAIMBAULT; LAVANDIER; BÉRENGIER, 2003).

Os estudos mencionados acima demonstram a necessidade de se calibrar os descritores sonoros para cada região específica, considerando seu contexto social e cultural. Tendo em vista essa lacuna, neste trabalho são apresentadas calibrações do descritor sonoro LAeq,T para espaços urbanos abertos do município de Belo Horizonte. Essas calibrações foram estabelecidas no trabalho de doutorado realizado por Hirashima (2014). A tese de Hirashima (2014), intitulada "Percepção sonora e térmica e avaliação de conforto em espaços urbanos abertos do município de Belo Horizonte MG, Brasil" aborda também as análises referentes à percepção sonora e ao conforto acústico e suas inter-relações com o conforto térmico.

\section{Objetivo}

O objetivo deste artigo é analisar a resposta dos usuários de espaços urbanos abertos com relação à percepção sonora e à avaliação de conforto acústico, considerando dados coletados em campo durante o ano de 2013 em duas praças do município de Belo Horizonte, e fornecer faixas de percepção sonora e faixas de conforto acústico, definidas com base nessas respostas subjetivas.

\section{Método}

O processo de pesquisa foi dividido em três etapas principais, descritas a seguir.

${ }^{4} \mathrm{PHAN}, \mathrm{H}$. A. T. et al. Annoyance Caused by Road Traffic With and Without horn Sounds. Acoust Sci \& Tech, v. 30, n. 5, p. 327 37, 2009.

\section{Etapa de planejamento}

A etapa de planejamento iniciou-se com o processo de definição da amostra, que considerou a população adulta (de 20 a 59 anos) e residente ininterruptamente há mais de um ano no município.

A seleção das áreas de estudo considerou a variabilidade de fontes sonoras, tendo, porém, o trânsito de veículos como a principal fonte de ruído; o intenso fluxo de pessoas, com vistas a viabilizar a aplicação de grande número de formulários; e diferentes ambiências, associadas às diferentes percepções de conforto global. As diferentes ambiências foram representadas por características contrastantes da morfologia urbana, como arborização, fator de visão do céu, altura dos edifícios, tipo de cobertura do solo e presença de fontes de água, e por diferentes usos predominantes do espaço - espaço de permanência (lazer) e espaço de passagem (deslocamento). Diante dessas características, optou-se pela realização dos levantamentos de campo nas Praças da Liberdade e Sete de Setembro (Figuras 1 e 2). A Praça da Liberdade é uma área menos verticalizada, com maior fator de visão do céu, com muitas fontes de água, com muita área verde e solo permeável em grande parte de sua extensão. É um espaço predominantemente de permanência (lazer). Já a Praça Sete de Setembro é área muito verticalizada, com menor fator de visão do céu, sem fontes de água, com poucas árvores e com solo quase todo pavimentado. É um espaço predominantemente de passagem (deslocamento).

Em cada uma das praças, com vistas à definição dos pontos de medição, foram realizados levantamentos prévios dos níveis de pressão sonora. Assim, objetivando a abrangência de grande parte das variações sonoras locais, espacialmente, dois pontos foram selecionados para a medição e para a aplicação dos formulários: um no local de maior nível de pressão sonora, e outro no local de menor nível de pressão sonora. Ao redor de cada ponto de medição foi delimitada uma área com fita zebrada (raio de medição, $\mathrm{rm}=1,5 \mathrm{~m}$ ) na qual apenas a pessoa responsável pela medição tinha acesso aos equipamentos. A delimitação dessa área visou a eliminar as eventuais interferências na medição dos níveis sonoros devido à proximidade de pessoas. Da mesma forma, no entorno de cada um dos pontos de medição, determinou-se uma área para aplicação dos formulários (raio de aplicação, ra=30 $\mathrm{m}$ ), dentro da qual a exposição dos pedestres aos níveis sonoros seria semelhante aos registros feitos pelo equipamento. 
Figura 1 - Praça da Liberdade

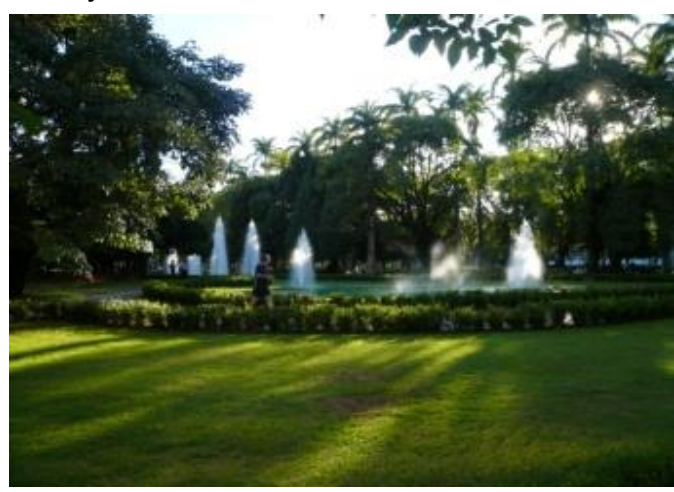

(a)

Figura 2 - Praça Sete de Setembro

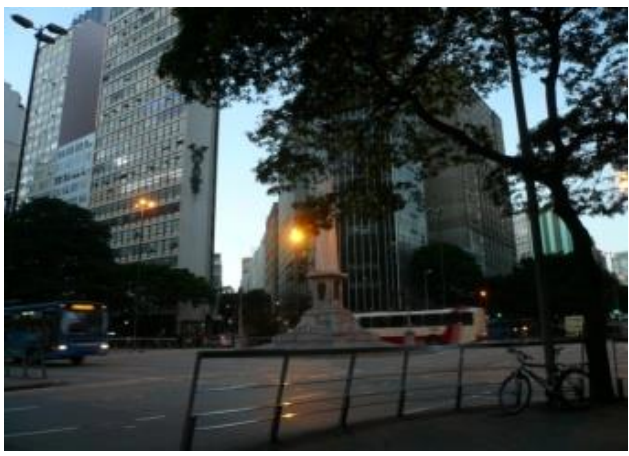

(a)

$\mathrm{Na}$ definição da época do ano em que seriam realizados os levantamentos de campo, considerouse a possibilidade de se obter diferentes percepções acústicas nas diferentes estações do ano. Dessa forma, a etapa de coleta de dados ocorreu nos meses de março (verão) e julho (inverno) de 2013. Buscando ainda registrar a maior amplitude sonora possível, temporalmente, a coleta de dados (medições acústicas e aplicação de formulários) foi realizada durante 10 horas seguidas, em cada um dos dias de coleta.

Na etapa de planejamento também foram definidas as variáveis a serem coletadas: variáveis acústicas (níveis de pressão sonora equivalentes contínuos ponderados - LAeq,1min); variáveis individuais (idade e sexo) e variáveis subjetivas (percepção do volume sonoro e avaliação de conforto acústico). Além dessas informações foram coletados alguns dados para controle, os quais se relacionam aos aspectos físicos, psicológicos e culturais que podem influenciar nas respostas dos indivíduos (como sensibilidade aos sons, local de moradia/bairro e profissão/ocupação).

Para a quantificação das sensações acústicas, optou-se pela utilização do índice nível de pressão sonora equivalente contínuo, ponderado na curva A (LAeq,T), definido pela ISO 1996-1

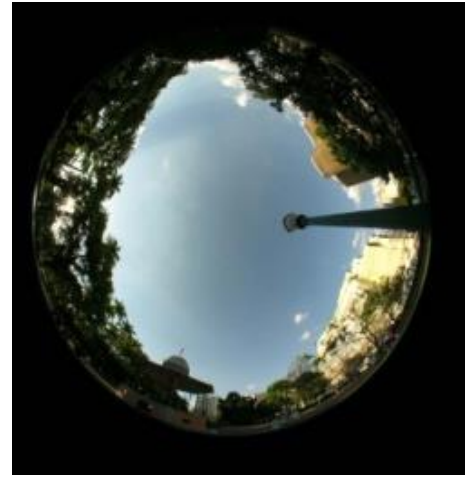

(b)

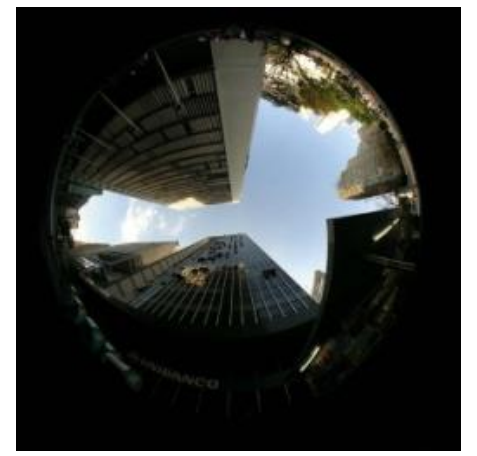

(b)

(INTERNATIONAL..., 2003a) e mencionado na ISO 1996-2 (INTERNATIONAL..., 2007). Esse descritor sonoro é facilmente obtido mediante medições in loco e tem sido muito adotado para a avaliação do ruído em comunidades, sendo, inclusive, o descritor utilizado na norma brasileira NBR 10151 (ABNT, 2000). Além disso, o LAeq,T se correlaciona bem com a percepção acústica e com o incômodo a ela relacionado (BOTTELDOOREN; DE COENSEL; DE MUER, 2006; SATO et al., $1999^{5}$ apud BANGJUN; LILI; GUOQUING, 2003).

A elaboração da parte do formulário referente à percepção do volume do ambiente sonoro e à avaliação de conforto acústico considerou os estudos da The International Commission on the Biological Effects of Noise (FIELDS et al., 2001), a ISO/TS 15666 (INTERNATIONAL..., 2003b), que especifica um método para medir o incômodo causado pelo ruído em residências por meio de pesquisas socioacústicas, e os estudos de Pereira (2003). As questões e escalas utilizadas são apresentadas no Quadro 1. Com vistas a tornar a coleta de dados mais eficiente, utilizou-se um

${ }^{5}$ SATO, T. et al. Road Traffic Noise in Relation to Average noise Level, Number of Events and Maximum Noise Level. Journal of Sound and Vibration, v. 223, n. 5, p. 775-84, 1999. 
formulário único, anônimo, contendo questões abertas e fechadas, com as duas primeiras questões eliminatórias e com as últimas questões com dados possíveis de serem coletados pelo entrevistador por meio de observação. Os formulários válidos, ou seja, aqueles não eliminados nas duas Primeiras questões e, portanto, considerados na pesquisa, abrangeram indivíduos residentes em Belo Horizonte, que estavam há mais de 30 min na área de estudo e que não apresentavam visivelmente problemas de audição ou nenhuma das situações previamente estabelecidas que alterassem a percepção de sensações acústicas no momento das entrevistas (como, por exemplo, estar utilizando fones de ouvido ou estar falando ao celular anteriormente à abordagem para a entrevista).

A escolha dos instrumentos de medição e também os procedimentos utilizados para obtenção das variáveis medidas observaram as recomendações da norma NBR 10151 (ABNT, 2000). Anteriormente à realização dos levantamentos de campo, todos os instrumentos de medição utilizados foram calibrados e aferidos, assim como os formulários e os procedimentos gerais de coleta de dados foram testados por meio de pesquisas exploratórias e pré-testes realizados em campo. Ambos os levantamentos de campo foram precedidos de treinamento da equipe.

\section{Etapa de coleta de dados}

A etapa de coleta de dados ocorreu nos dias 11 de março de 2013, na Praça da Liberdade, e 13 de março de 2013, na Praça Sete de Setembro; e nos dias 8 de julho de 2013, na Praça da Liberdade, e 9 de julho de 2013, na Praça Sete de Setembro, no período das 7 às $17 \mathrm{~h}$.
Os instrumentos de medição (medidores de níveis de pressão sonora - marca HOMIS, modelo SL401) foram montados em tripés, a 1,2 $\mathrm{m}$ do piso e a pelo menos $2 \mathrm{~m}$ de quaisquer superfícies refletoras, como muros, paredes, etc. Não foram realizadas medições na ocorrência de chuvas, trovoadas ou quaisquer outros fenômenos da natureza que pudessem causar interferências audíveis durante os registros. Anteriormente aos trabalhos de campo, os medidores de pressão sonora foram devidamente ajustados com o calibrador acústico, sendo o mesmo procedimento realizado após a coleta de dados, para conferência da calibração do equipamento. Os valores de $\mathrm{L}_{\text {Aeq, } 1 \text { min }}$ foram registrados a cada $5 \mathrm{~min}$.

\section{Etapa de tratamento dos dados coletados}

A etapa de tratamento dos dados coletados iniciouse com o cálculo do $\mathrm{L}_{\mathrm{Aeq}, 10 \mathrm{~h}} \mathrm{e}$ dos níveis estatísticos de acústica $\left(\mathrm{L}_{10}, \mathrm{~L}_{50}, \mathrm{~L}_{90}\right)$. $\mathrm{O}$ cálculo do $\mathrm{L}_{\text {Aeq,10h }}$, com base nos valores registrados em campo, foi realizado por meio da utilização da equação estabelecida pela NBR 10.151. Utilizou-se uma planilha do Microsoft Excel ${ }^{\circledR}$ para o cálculo dos valores de $\mathrm{L}_{\mathrm{Aeq}, 10 \mathrm{~h}} \mathrm{e}$ dos níveis estatísticos de acústica $\left(\mathrm{L}_{10}, \mathrm{~L}_{50}\right.$ e $\left.\mathrm{L}_{90}\right)$. A análise descritiva apresentada neste artigo foi realizada por meio da utilização do Microsoft Excel ${ }^{\circledR}$.

Visando às calibrações do descritor sonoro $\mathrm{L}_{\mathrm{Aeq}, \mathrm{T}}$, foram empregados modelos de regressão, com a utilização de todo o conjunto de dados (de ambas as praças, de ambos os pontos e para ambas as estações).

\section{Quadro 1 - Questões e escalas referentes à percepção do volume do ambiente sonoro e à avaliação de} conforto acústico

\begin{tabular}{|l|l|l|}
\hline & \multicolumn{1}{|c|}{ Questões } & \multicolumn{1}{c|}{ Escalas } \\
\hline $\begin{array}{l}\text { Percepção do volume do } \\
\text { ambiente sonoro }\end{array}$ & $\begin{array}{l}\text { O que você acha do volume do } \\
\text { som ambiente neste momento? }\end{array}$ & $\begin{array}{l}\text { [1] Nem tinha percebido } \\
\text { [2] Baixo } \\
\text { [3] Normal } \\
\text { [4] Um pouco alto } \\
\text { [5] Muito alto }\end{array}$ \\
\hline \multirow{2}{*}{ Avaliação do conforto acústico } & $\begin{array}{l}\text { [1] Confortável } \\
\text { Com relação ao ambiente sonoro } \\
\text { [2] Um pouco desconfortável } \\
\text { [3] Desconfortável } \\
\text { [4] Muito desconfortável }\end{array}$ \\
\hline
\end{tabular}

Nota: ${ }^{1}$ Devido à necessidade de aplicação de questionários em campo, a linguagem científica foi adaptada à popular, razão pela qual foram utilizados, nesta pesquisa, em vez dos termos "Forte" e "Fraco", os termos "Alto" e "Baixo", correntemente usados pela população para se referir aos sons de grande e de pequena intensidade, respectivamente. Salienta-se, portanto, que, neste trabalho, os termos "Alto" e "Baixo" não estão relacionados à altura (frequência) dos sons, mas sim à intensidade (amplitude) destes. 
Para verificar o efeito do índice $\mathrm{L}_{\mathrm{Aeq}, \mathrm{T}}$ sobre a percepção do volume sonoro, foi ajustada uma regressão logística ordinal considerando as chances proporcionais parciais (PETERSON; HANRREL, 1990). Com vistas a um melhor ajuste do modelo de regressão, a escala da percepção do volume sonoro foi reclassificada para três categorias: "Baixo", "Normal" e "Alto". A categoria "Baixo" inclui "Nem tinha percebido" e "Baixo", a categoria "Normal" inclui "Normal", enquanto a categoria "Alto" inclui "Um pouco alto" e "Muito alto". Para verificar a qualidade do ajuste foi calculado o pseudo $\mathrm{R}^{2}$ de Nagelkerke (NAGELKERKE, 1991) e a acurácia nas predições.

Objetivando verificar o efeito do índice $\mathrm{L}_{\text {Aeq }}$ sobre a avaliação subjetiva de conforto acústico, foi ajustada uma regressão logística (AGRESTI, 2002). Visando a um melhor ajuste do modelo de regressão, a avaliação subjetiva do conforto acústico foi reclassificada para duas categorias: "Confortável" e "Desconfortável". A categoria "Confortável" inclui apenas a categoria "Confortável". A categoria "Desconfortável" inclui as categorias "Um pouco desconfortável”, "Desconfortável" e "Muito desconfortável". Para testar a adequabilidade do modelo, foi realizado o teste de Hosmer-Lemeshow (HOSMER; LEMESHOW, 2000), calculado o pseudo $\mathrm{R}^{2}$ de Nagelkerke (NAGELKERKE, 1991) e a acurácia nas predições.

\section{Apresentação e análise dos resultados}

Os resultados apresentados e analisados foram obtidos com a aplicação de um total de 1.693 formulários válidos: 748 na Praça da Liberdade e 945 na Praça Sete de Setembro.

\section{Variáveis acústicas medidas em campo}

As Figuras 3 e 4 apresentam, para ambas as praças, as séries de dados medidos, em março e julho, para ambos os pontos de medição.

Os valores de mínimo, $\mathrm{L}_{\mathrm{Aeq}, 10 \mathrm{~h}}$, máximo, amplitude, desvio padrão, coeficientes de variação, $\mathrm{L}_{10,10 \mathrm{~h}}, \mathrm{~L}_{50,10 \mathrm{~h}}, \mathrm{~L}_{90,10 \mathrm{~h}}$, e da diferença $\mathrm{L}_{10}-\mathrm{L}_{90}$ são apresentados na Tabela 1 , para os $\mathrm{L}_{\text {Aeq, } 1 \text { min }}$, para ambos os pontos de medição em cada área, para março e julho.

Figura 3 - Série temporal de dados medidos de níveis de pressão sonora equivalentes $-\mathrm{L}_{\text {Aeq }}, 1 \mathrm{~min}$, março (verão)

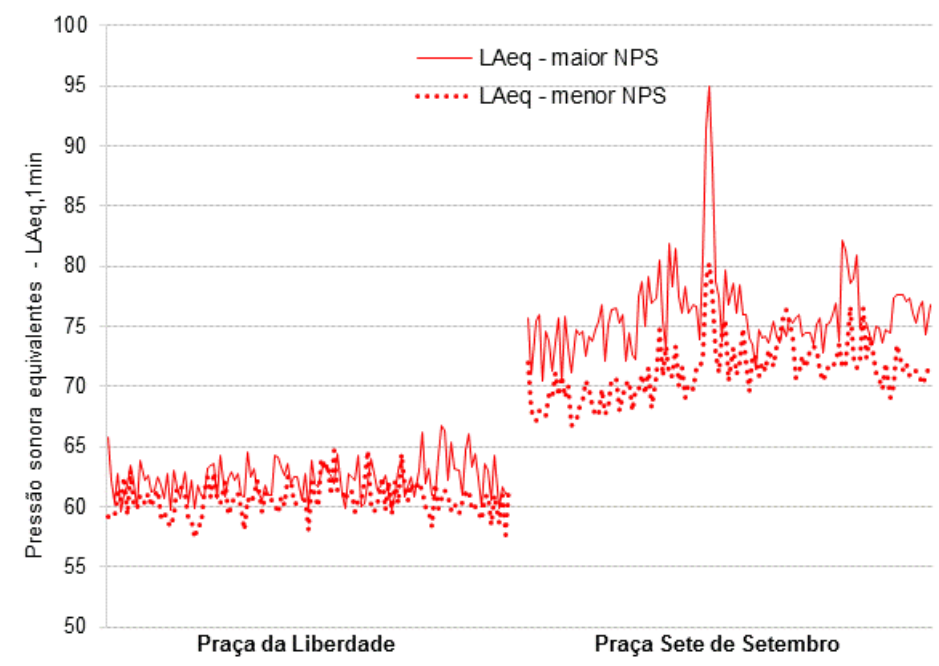


Figura 4 - Série temporal de dados medidos de níveis de pressão sonora equivalentes - $\mathrm{L}_{\text {Aeq }}, 1 \mathrm{~min}$, julho (inverno)

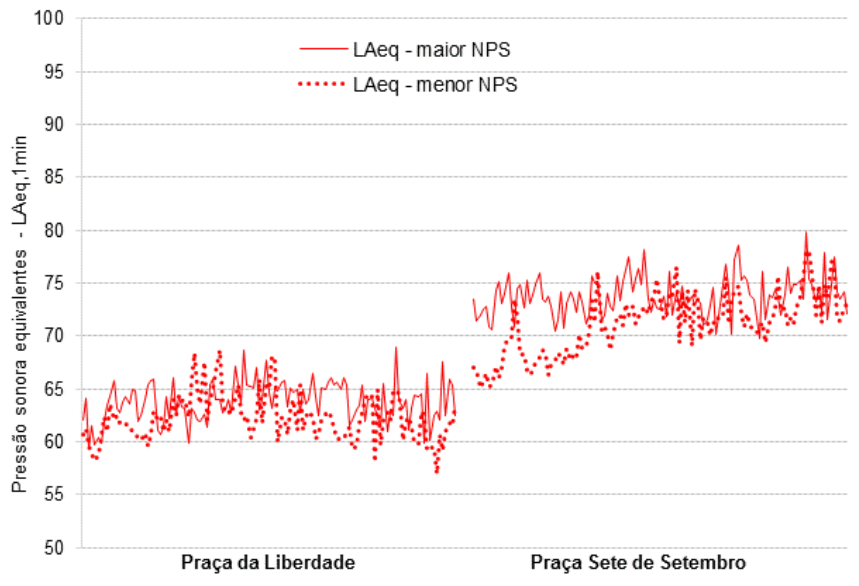

Tabela 1 - Valores dos níveis de pressão sonora equivalentes -1 min - ponderados na curva A $\left(\mathrm{L}_{\text {Aeq, }}\right.$, $1 \mathrm{~min}$ ) para os levantamentos de campo de verão e de inverno

\begin{tabular}{|c|c|c|c|c|c|c|c|c|}
\hline & \multicolumn{4}{|c|}{ Março (Verão) } & \multicolumn{4}{|c|}{ Julho (Inverno) } \\
\hline & \multicolumn{2}{|c|}{ Praça da Liberdade } & \multicolumn{2}{|c|}{$\begin{array}{c}\text { Praça Sete de } \\
\text { Setembro }\end{array}$} & \multicolumn{2}{|c|}{ Praça da Liberdade } & \multicolumn{2}{|c|}{$\begin{array}{c}\text { Praça Sete de } \\
\text { Setembro }\end{array}$} \\
\hline & $\begin{array}{c}\mathbf{L}_{\text {Aeq,1min }} \\
\text { dB(A) } \\
\text { (menor } \\
\text { NPS) } \\
\end{array}$ & $\begin{array}{c}\mathbf{L}_{\text {Aeq,1min }} \\
\text { dB(A) } \\
\text { (maior } \\
\text { NPS) } \\
\end{array}$ & $\begin{array}{c}\mathbf{L}_{\text {Aeq,1min }} \\
\text { dB(A) } \\
\text { (menor } \\
\text { NPS) } \\
\end{array}$ & $\begin{array}{c}\mathbf{L}_{\text {Aeq,1min }} \\
\text { dB(A) } \\
\text { (maior } \\
\text { NPS) } \\
\end{array}$ & $\begin{array}{c}\mathbf{L}_{\text {Aeq,1min }} \\
\text { dB(A) } \\
\text { (menor } \\
\text { NPS) } \\
\end{array}$ & $\begin{array}{c}\mathbf{L}_{\text {Aeq,1min }} \\
\text { dB(A) } \\
\text { (maior } \\
\text { NPS) } \\
\end{array}$ & $\begin{array}{c}\mathbf{L}_{\text {Aeq,1min }} \\
\text { dB(A) } \\
\text { (menor } \\
\text { NPS) } \\
\end{array}$ & $\begin{array}{c}\mathbf{L}_{\text {Aeq,1min }} \\
\text { dB(A) } \\
\text { (maior } \\
\text { NPS) } \\
\end{array}$ \\
\hline Minimo & 57,3 & 59,6 & 66,7 & 70,4 & 57,0 & 59,3 & 65,1 & 69,8 \\
\hline $\mathrm{L}_{\text {Aeq, } 10 \mathrm{~h}}$ & 60,6 & 62,2 & 71,3 & 76,0 & 62,2 & 63,8 & 71,1 & 73,7 \\
\hline Máximo & 64,7 & 66,7 & 80,2 & 95 & 68,6 & 68,9 & 78,0 & 79,8 \\
\hline Amplitude & 7,4 & 7,1 & 13,5 & 24,6 & 11,6 & 9,6 & 12,9 & 10,0 \\
\hline DP & 1,4 & 1,5 & 2,4 & 3,5 & 2,2 & 1,9 & 2,9 & 1,9 \\
\hline $\mathrm{CV}(\%)$ & 2,3 & 2,4 & 3,4 & 4,5 & 3,5 & 3,0 & 4,1 & 2,5 \\
\hline $\mathrm{L}_{10,10 \mathrm{~h}}$ & 62,2 & 64,2 & 74,2 & 78,7 & 64,9 & 65,9 & 74,8 & 76,1 \\
\hline $\mathrm{L}_{50,10 \mathrm{~h}}$ & 60,5 & 62,2 & 71,1 & 75,4 & 62,1 & 63,9 & 71,3 & 73,7 \\
\hline $\mathrm{L}_{90,10 \mathrm{~h}}$ & 58,9 & 60,3 & 68,2 & 72,8 & 59,6 & 61,3 & 67,0 & 71,5 \\
\hline $\mathrm{L}_{10}-\mathrm{L}_{90}$ & 3,3 & 3,9 & 6,2 & 5,9 & 5,3 & 4,6 & 7,8 & 4,6 \\
\hline
\end{tabular}

Com relação aos valores do $\mathrm{L}_{\text {Aeq,1min }}$ medidos, em março e julho, os valores mais elevados foram registrados na Praça Sete de Setembro. Nota-se que, na Praça da Liberdade, além de os valores de $\mathrm{L}_{\text {Aeq,10h }}$ serem mais baixos para ambos os pontos de medição, a menor amplitude dos valores medidos mostra que o nível sonoro não é tão variável quanto na Praça Sete de Setembro, na qual a amplitude dos valores medidos foi maior, o que indica maior variabilidade dos níveis sonoros, e na qual também os valores de $\mathrm{L}_{\mathrm{Aeq}, 10 \mathrm{~h}}$, foram bastante elevados. Tanto os valores de $\mathrm{L}_{90,10 \mathrm{~h}}$ quanto os valores da diferença $\mathrm{L}_{10}-\mathrm{L}_{90}$, ambos bastante relacionados à sensação de incômodo na literatura, o primeiro por representar a condição mais característica do ruído medido e o segundo por representar as variações bruscas dos níveis sonoros, foram iguais ou mais elevados nos registros realizados para a Praça Sete de Setembro. Observa-se um pico nos dados registrados na Praça
Sete de Setembro, em março, o qual não foi retirado da base de dados por se referir à passagem de um caminhão aberto de manifestação popular com uso de microfone e caixas de sons potentes. Esse tipo de veículo é frequentemente utilizado nessa área, representando uma situação bem típica para a região.

A Tabela 2 mostra a comparação do descritor sonoro $\mathrm{L}_{\mathrm{Aeq}}$ entre as estações, e a Tabela 4 mostra a comparação do descritor sonoro $\mathrm{L}_{\mathrm{Aeq}}$ entre as praças.

Pela análise da Tabela 3 pode-se verificar que em março a média do índice $\mathrm{L}_{\text {Aeq }}$ foi de $68,6 \mathrm{~dB}(\mathrm{~A})$, enquanto em julho a média do índice $\mathrm{L}_{\mathrm{Aeq}}$ foi de $68,1 \mathrm{~dB}(\mathrm{~A})$, sendo essa diferença não significativa (valor- $p=0,427$ ). Já a Tabela 4 mostra que na Praça da Liberdade a média do índice $\mathrm{L}_{\text {Aeq }}$ foi de 62,3 $\mathrm{dB}(\mathrm{A})$, enquanto na Praça Sete de Setembro a 
média do índice $\mathrm{L}_{\mathrm{Aeq}}$ foi de $73,2 \mathrm{~dB}(\mathrm{~A})$, sendo essa diferença significativa (valor-p=0,000).

\section{Variáveis subjetivas coletadas por meio da aplicação de formulário}

A seguir são apresentados os gráficos referentes à resposta dos usuários, para ambas as estações, para ambas as praças, com relação à percepção do volume sonoro (Figuras 5 e 6) e à avaliação de conforto acústico (Figuras 7 e 8).

Nas condições acústicas apresentadas no item Variáveis acústicas medidas em campo, para o levantamento de campo de março, na Praça da Liberdade, a maioria dos entrevistados consideraram o volume sonoro existente no momento das entrevistas como "Normal", afirmando que estavam "Confortáveis". Já na Praça Sete de Setembro, 65\% dos entrevistados consideraram o volume sonoro do momento da entrevista "Alto" em algum grau, dos quais $29,6 \%$ o consideraram "Muito alto". Nesta praça, 67,6\% dos entrevistados reportaram que estavam "Desconfortáveis", em algum grau. Apenas 32,4\% dos entrevistados afirmaram estar "Confortáveis". Ao analisar a série temporal do índice $\mathrm{L}_{\text {Aeq, } 1 \mathrm{~min}}$ apresentada na Figura 3, pode-se notar que na Praça da Liberdade os valores medidos em campo oscilaram em torno dos $60 \mathrm{~dB}(\mathrm{~A})$, estando, em grande parte do período considerado, um pouco acima desse valor, que é o limite diurno estabelecido para conforto acústico em ambientes externos pela NBR 10151, para área mista, com vocação comercial e administrativa. Era de se esperar, portanto, que grande parte das pessoas reportassem desconforto também nessa situação. Isso demonstra certo grau de tolerância por parte dos usuários urbanos com relação aos elevados níveis sonoros existentes na Praça da Liberdade. Já a série temporal do $\mathrm{L}_{\mathrm{Aeq}, 1 \mathrm{~min}}$ referente aos dados medidos para a Praça Sete de Setembro oscila na faixa entre 65 e $80 \mathrm{~dB}(\mathrm{~A})$, representando níveis sonoros bem acima do limite estabelecido pela NBR 10151, o que pode explicar o alto percentual de pessoas que consideraram o volume sonoro dessa praça no dia da entrevista como "Muito alto" e "Desconfortável".

Tabela 2 - Comparação do descritor $L_{A e q}(d B(A))$ entre as duas estações (representadas pelos dois levantamentos de campo: março - verão; julho - inverno)

\begin{tabular}{c|l|c|c|c|c|c|c|c}
\hline Índice & Estação & $\mathbf{N}$ & Média & E.P. & $\mathbf{1}^{\mathbf{0}} \mathbf{Q}$ & $\mathbf{2}^{\mathbf{0}} \mathbf{Q}$ & $\mathbf{3}^{\mathbf{0}} \mathbf{Q}$ & Valor-p $^{\mathbf{1}}$ \\
\hline \multirow{2}{*}{ Índice $\mathrm{L}_{\text {Aeq }}$} & Verão & 833 & 68,6 & 0,2 & 62,0 & 70,0 & 74,0 & \multirow{2}{*}{0,427} \\
\cline { 2 - 10 } & Inverno & 858 & 68,1 & 0,2 & 63,0 & 68,0 & 73,0 & \\
\hline
\end{tabular}

Nota: ${ }^{1}$ Teste de Mann-Whitney.

Tabela 3 - Comparação do descritor $\mathrm{L}_{\mathrm{Aeq}}(\mathrm{dB}(\mathrm{A}))$ entre as duas áreas de estudo

\begin{tabular}{c|l|c|c|c|c|c|c|c}
\hline \multicolumn{1}{c|}{ Índice } & Praça & $\mathbf{N}$ & Média & $\mathbf{E . P .}$ & $\mathbf{1}^{\mathbf{0}} \mathbf{Q}$ & $\mathbf{2}^{\mathbf{0}} \mathbf{Q}$ & $\mathbf{3}^{\mathbf{0}} \mathbf{Q}$ & Valor-p $^{\mathbf{1}}$ \\
\hline \multirow{2}{*}{ Índice $\mathrm{L}_{\text {Aeq }}$} & Liberdade & 748 & 62,3 & 0,1 & 61,0 & 62,0 & 64,0 & \multirow{2}{*}{0,000} \\
\cline { 2 - 8 } & $\begin{array}{l}\text { Sete de } \\
\text { Setembro }\end{array}$ & 943 & 73,2 & 0,1 & 71,0 & 73,0 & 75,0 & \multirow{2}{*}{} \\
\hline
\end{tabular}

Nota: ${ }^{1}$ Teste de Mann-Whitney.

Figura 5 - Porcentagem de resposta dos entrevistados sobre a percepção do volume sonoro - março (verão)

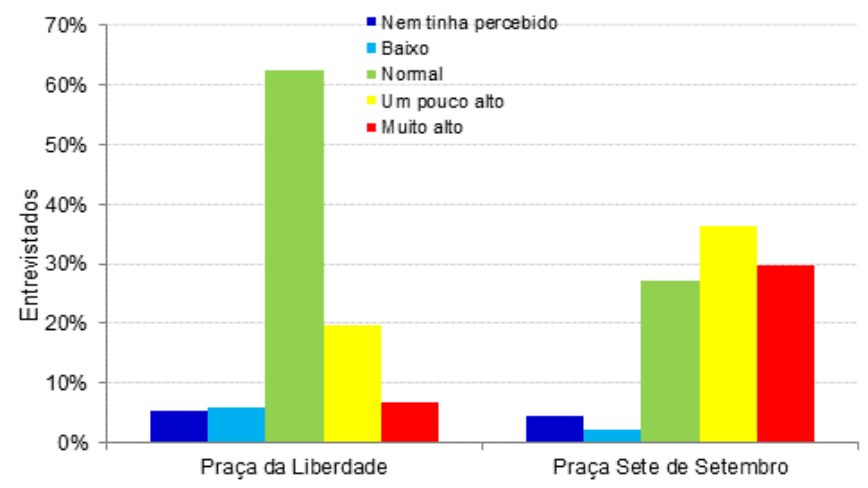

14 Hirashima, S. Q. da S.; Assis, E. S. de. 
Figura 6 - Porcentagem de resposta dos entrevistados sobre a percepção do volume sonoro - julho (inverno)

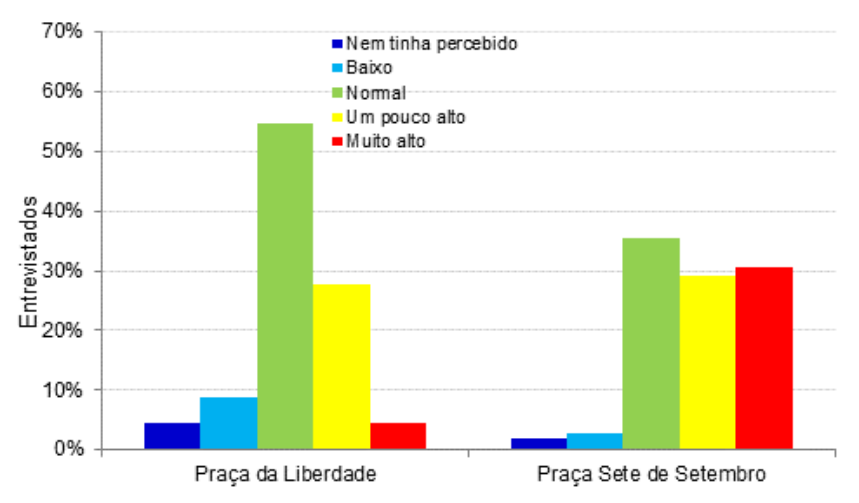

Figura 7 - Porcentagem de resposta dos entrevistados sobre a avaliação de conforto acústico - março (verão)

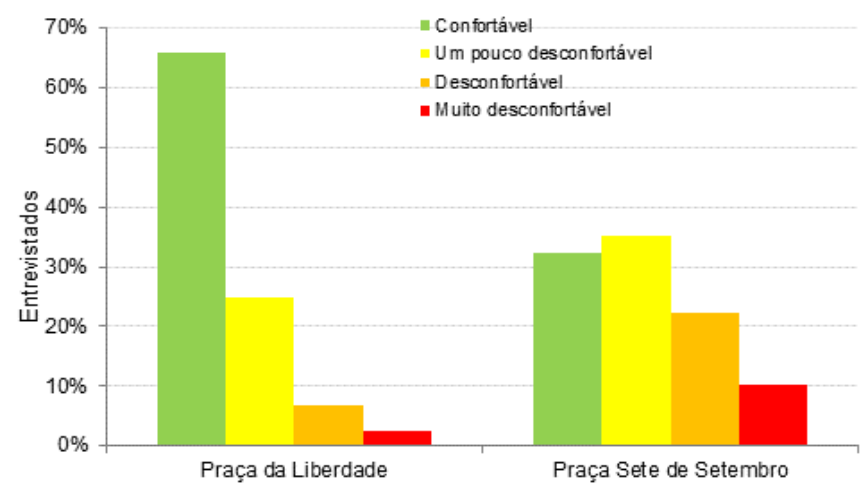

Figura 8 - Porcentagem de resposta dos entrevistados sobre a avaliação de conforto acústico - julho (inverno)

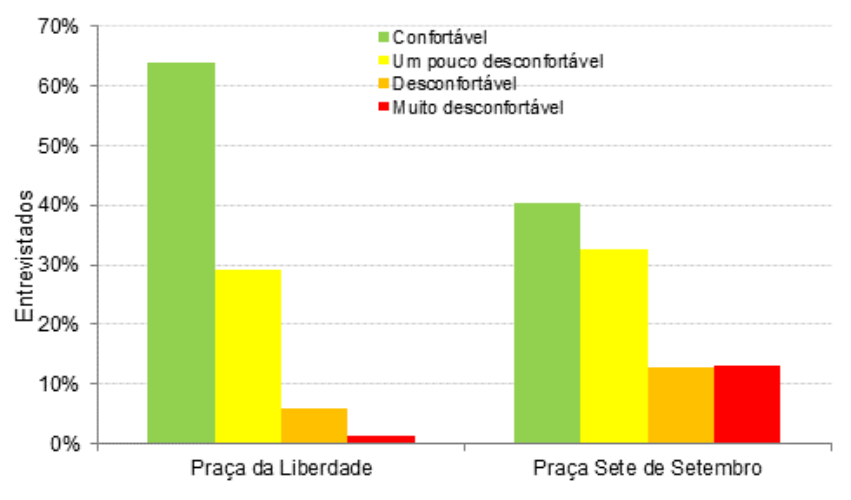

Nas condições acústicas apresentadas no item Variáveis acústicas medidas em campo, para o levantamento de campo de julho, em ambas as praças, a maioria dos entrevistados consideraram o volume sonoro existente no momento das entrevistas como "Normal", afirmando que estavam "Confortáveis". Ao analisar a série temporal do índice $\mathrm{L}_{\text {Aeq, } 1 \mathrm{~min}}$ apresentada na Figura 4, pode-se notar que, assim como no levantamento de campo de março, na Praça da Liberdade, os valores medidos em campo oscilaram em torno dos $60 \mathrm{~dB}(\mathrm{~A})$, e que, da mesma maneira, mais de $60 \%$ dos entrevistados disseram estar "Confortáveis" nas condições acústicas existentes no momento da entrevista. Isso demonstra igualmente certo grau de tolerância por parte dos usuários urbanos com relação aos níveis sonoros existentes na Praça da Liberdade. Mas, também a série temporal do $\mathrm{L}_{\text {Aeq,1min }}$ referente aos dados medidos para a Praça Sete de Setembro oscila, assim como no 
levantamento de campo de março, na faixa de 65 a $80 \mathrm{~dB}(\mathrm{~A})$. Porém, em dissonância com os resultados apresentados para os levantamentos de campo de março, a maioria dos entrevistados consideraram o volume sonoro existente no momento das entrevistas como "Normal", afirmando que estavam "Confortáveis". Essa avaliação pode ser explicada pelo fato de que no levantamento de campo de março foram mais altos os valores obtidos para a amplitude do $\mathrm{L}_{\text {Aeq, } 1 \mathrm{~min}}$, para a diferença entre $\mathrm{L}_{10}$ e $\mathrm{L}_{90}$ (exceto para o ponto de menores níveis de pressão sonora (NPS)) e para o $\mathrm{L}_{90}$. Diferenças na paisagem sonora entre as estações (verão e inverno) também podem explicar essa diferença nas respostas subjetivas às condições acústicas (HIRASHIMA, 2014). Adicionalmente, tendo em vista que no levantamento de campo de março as condições térmicas eram mais adversas (desconforto térmico por calor em grande parte do dia, conforme
Hirashima (2014)), outra possível explicação para essa avaliação (percepção das condições acústicas também como desconfortáveis) seriam os fatos de o conforto global influenciar na avaliação isolada de conforto acústico, conforme estudos de Raimbault, Lavandier e Bérengier (2003), e de a percepção ser multissensorial, conforme estudos de Viollon, Lavandier e Drake (2002) e Pereira (2003), dentre outros, todos mencionados na introdução deste artigo.

As Figuras 9 a 12 apresentam, para cada uma das estações e para cada uma das áreas, a relação entre a percepção acústica dos entrevistados e o índice de conforto acústico $\mathrm{L}_{\text {Aeq }}$, para cada uma das faixas medidas desse índice. Similarmente, as Figuras 13 a 16 apresentam, para cada uma das estações e para cada uma das áreas, a relação entre a avaliação de conforto acústico dos entrevistados e o índice de conforto acústico $\mathrm{L}_{\text {Aeq }}$, para cada uma das faixas medidas desse índice.

Figura 9 - Distribuição percentual das categorias de percepção acústica em função dos valores de $L_{\text {Aeq }}$, em $\mathrm{dB}(\mathrm{A})$, para a Praça da Liberdade, em março (verão)

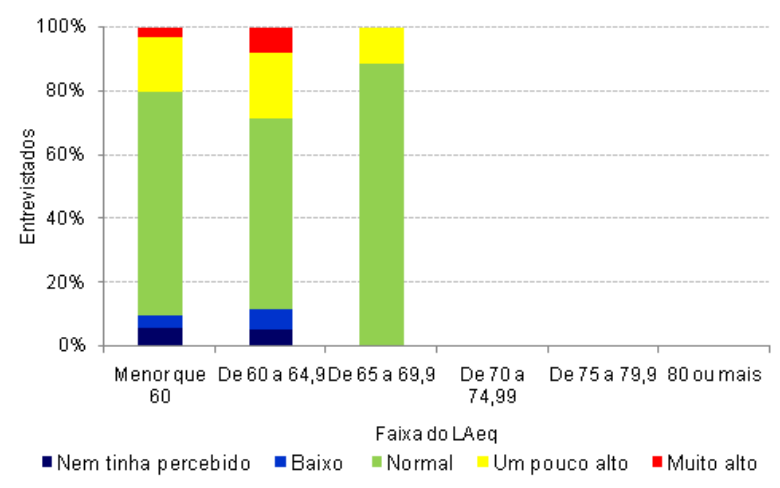

Figura 10 - Distribuição percentual das categorias de percepção acústica em função dos valores de $L_{\text {Aeq, }}$, em $\mathrm{dB}(\mathrm{A})$, para a Praça Sete de Setembro, em março (verão)

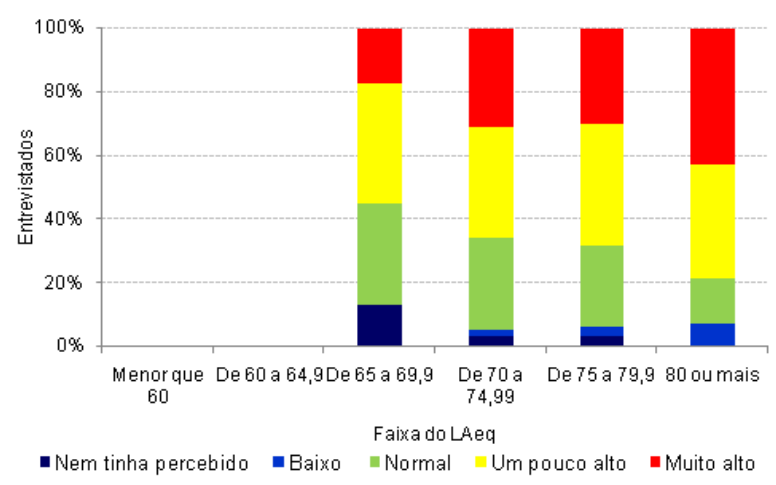

16 Hirashima, S. Q. da S.; Assis, E. S. de. 
Figura 11 - Distribuição percentual das categorias de percepção acústica em função dos valores de $L_{\text {Aeq, }}$, em $d B(A)$, para a Praça da Liberdade, em julho (inverno)

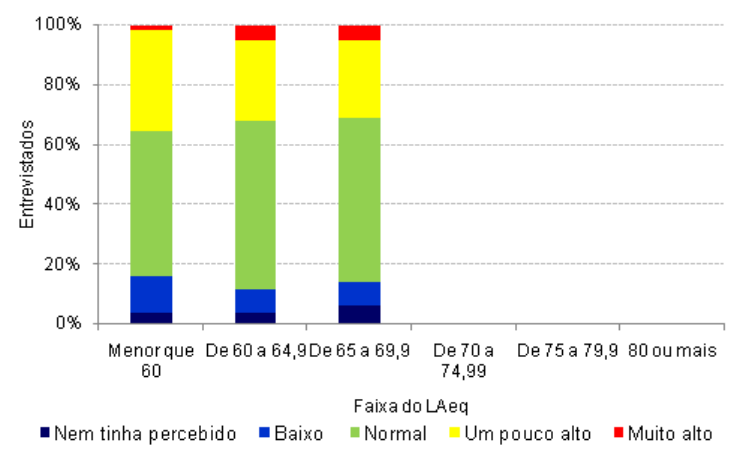

Figura 12 - Distribuição percentual das categorias de percepção acústica em função dos valores de $L_{\text {Aeq}}$, em $d B(A)$, para a Praça Sete de Setembro, em julho (inverno)

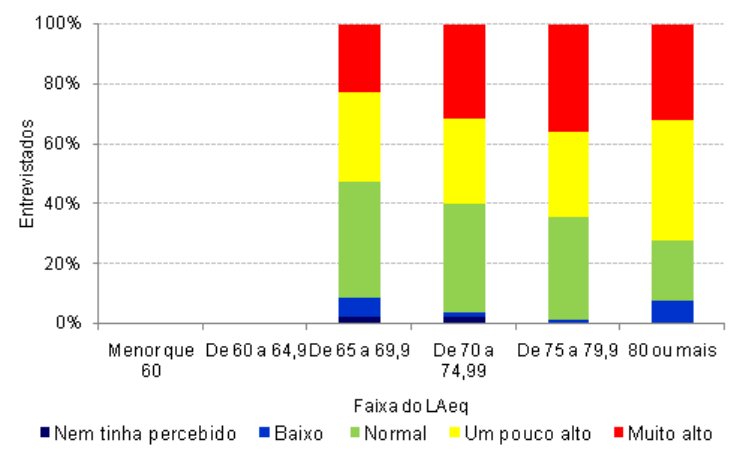

Figura 13 - Distribuição percentual das categorias de conforto acústico em função dos valores de $L_{\text {Aeq, }}$, em dB(A), para a Praça da Liberdade, em março (verão)

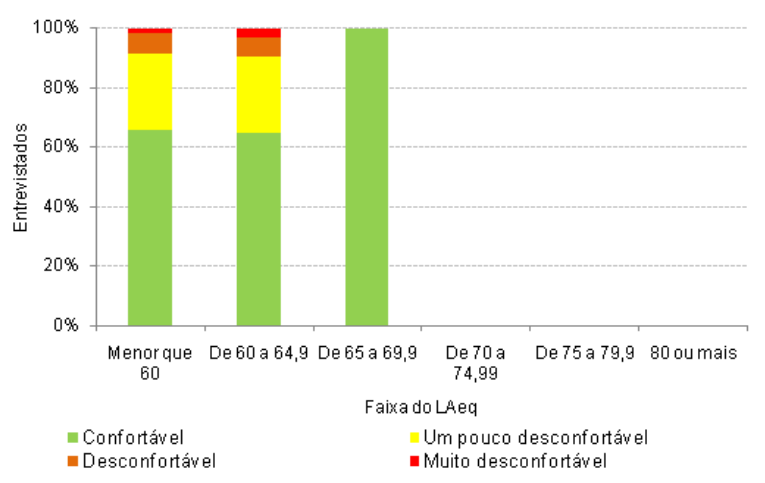

Figura 14 - Distribuição percentual das categorias de conforto acústico em função dos valores de $L_{\text {Aeq, }}$, em $d B(A)$, para a Praça Sete de Setembro, em março (verão)

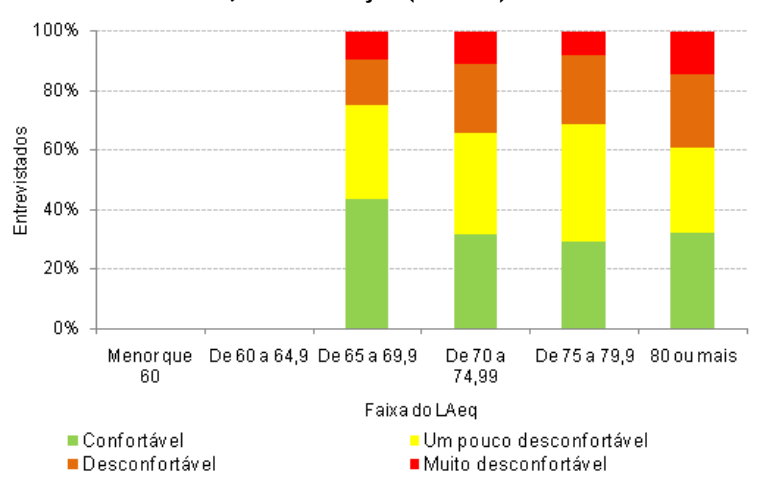


Figura 15 - Distribuição percentual das categorias de conforto acústico em função dos valores de $L_{\text {Aeq, }}$, em $\mathrm{dB}(\mathrm{A})$, para a Praça da Liberdade, em julho (inverno)

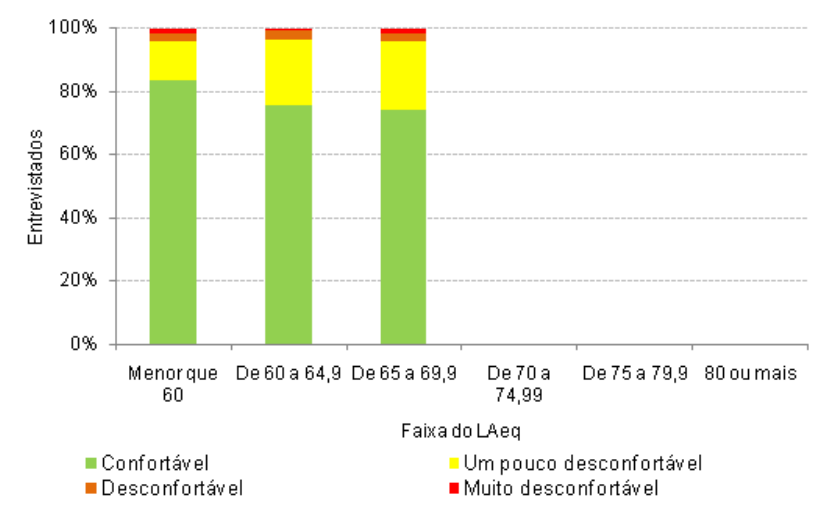

Figura 16 - Distribuição percentual das categorias de conforto acústico em função dos valores de $L_{\text {Aeq }}$, em dB(A), para a Praça Sete de Setembro, em julho (inverno)

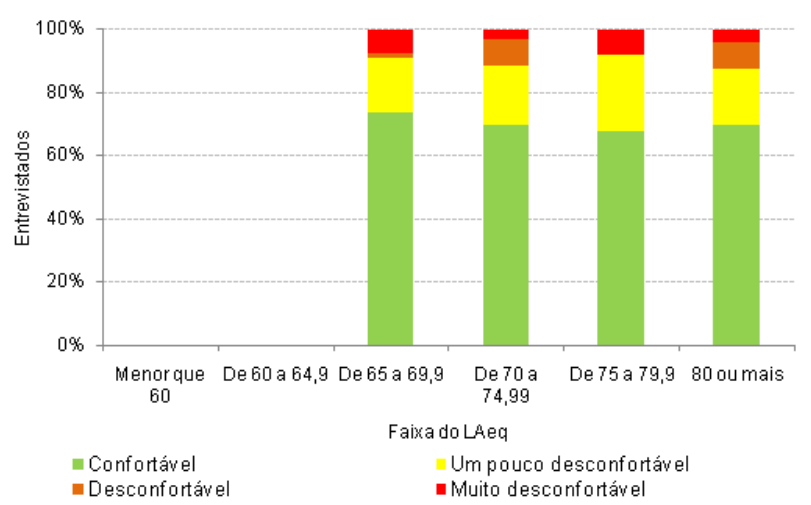

Tanto no levantamento de campo de março quanto no de julho, na faixa de 65 a $69 \mathrm{~dB}(\mathrm{~A})$, o percentual de pessoas que perceberam o som ambiente como "Normal" é maior na Praça da Liberdade do que na Praça Sete de Setembro (Figuras 9 a 12). Da mesma forma, o percentual de pessoas que se sentem "Confortáveis" também é maior na Praça da Liberdade (Figuras 13 a 16), ao se considerar as mesmas condições acústicas.

Esse fato confirma os resultados encontrados anteriormente e pode ser novamente explicado pela interação entre o conforto acústico e os outros fatores do ambiente - como o conforto visual e o conforto térmico, conforme estudos de Kang, Yang e Zhang (2004); Raimbault, Lavandier e Bérengier (2003); Pereira (2003); e Viollon, Lavandier e Drake (2002), mencionados na Introdução.

No levantamento de campo da Praça Sete de Setembro, o percentual de indivíduos que perceberam o som ambiente como "Normal" é maior no levantamento de campo de julho (inverno) do que no de março (verão), para todas as faixas analisadas (Figuras 10 e 12). Da mesma forma, o percentual de pessoas que se sentem
"Confortáveis" também é maior em julho do que em março, para todas as faixas analisadas (Figuras 14 e 16). Na Praça da Liberdade, o mesmo parece ocorrer, apesar de menos evidente (Figuras 9, 11, 13 e 15$)$.

De um modo geral, a análise dos gráficos apresentados (Figuras 9 a 16) mostra que, sob as mesmas condições acústicas, tanto no que diz respeito à percepção sonora quanto à avaliação de conforto acústico, os indivíduos tendem a ser mais tolerantes na Praça da Liberdade (melhor ambiência, melhores condições de conforto térmico) do que na Praça Sete de Setembro e tendem também a ser mais tolerantes em julho (inverno - condições térmicas mais amenas, conforme Hirashima (2014)) do que em março (verão - condição de desconforto térmico por calor em momentos do dia, conforme Hirashima (2014)).

Ao se comparar as respostas dos usuários com relação à percepção do volume sonoro com as respostas com relação à avaliação de conforto acústico, considerando as mesmas praças e as mesmas faixas do descritor sonoro $\mathrm{L}_{\mathrm{Aeq}}$, nota-se que, no levantamento de campo de março, ou 
período de verão (Figuras 9 e 13, para a Praça da Liberdade; e Figuras 10 e 14, para a Praça da Liberdade), essas respostas são bastantes semelhantes. Porém, no levantamento de campo de julho, ou período de inverno (Figuras 11 e 15, para a Praça da Liberdade; e Figuras 12 e 16, para a Praça da Liberdade), os usuários são mais tolerantes com relação à avaliação de conforto acústico do que com relação à percepção de volume sonoro, quando comparadas as mesmas áreas/praças e as mesmas faixas do descritor sonoro $\mathrm{L}_{\text {Aeq. }}$.

\section{Calibração do descritor sonoro $L_{\text {Aeq }}$ com relação às faixas de percepção do volume sonoro}

A Tabela 4 apresenta o ajuste da regressão logística ordinal com as chances proporcionais parciais, com vistas a analisar as relações entre o $\mathrm{L}_{\text {Aeq }}$ e a percepção do volume sonoro.

Avaliando o ajuste da regressão (Tabela 2), podese verificar que a cada unidade acrescida ao índice
$\mathrm{L}_{\text {Aeq }}$ a chance de a percepção sonora dos entrevistados ser classificada nas categorias "Normal" ou "Alto" aumenta 1,08 [1,04; 1,11] vez, se comparada à chance de esta percepção ser classificada na categoria "Baixo". Da mesma forma, a cada unidade acrescida ao índice $\mathrm{L}_{\text {Aeq }}$ a chance de a percepção sonora dos entrevistados ser classificada na categoria "Alto" aumenta 1,12 $[1,10 ; 1,14]$ vez, se comparada à chance de esta percepção ser classificada nas categorias "Normal" ou "Baixo". O índice $\mathrm{L}_{\text {Aeq }}$ foi capaz de explicar $10,4 \%$ das ocorrências da percepção do volume sonoro, sendo capaz de predizer $60,9 \%$ de respostas corretas.

A Figura 17 apresenta a calibração do índice $\mathrm{L}_{\text {Aeq }}$ para espaços urbanos abertos do município de Belo Horizonte, apresentando as probabilidades preditas para a percepção do volume sonoro com relação aos valores do índice $\mathrm{L}_{\text {Aeq. }}$ A Tabela 5 apresenta um resumo dos resultados referentes à calibração do $\mathrm{L}_{\text {Aeq }}$ com relação à percepção do volume sonoro.

Tabela 4 - Efeito do $L_{\text {Aeq }}$ sobre a percepção do volume sonoro

\begin{tabular}{c|c|c|c|c|c}
\hline Modelo & $\boldsymbol{\beta}$ & E.P.( $\boldsymbol{\beta})$ & Valor-p & O.R. & I.C. - 95\% \\
\hline LAeq: ( Prob[ Y > Baixo ] ) & 0,073 & 0,015 & 0,000 & 1,08 & {$[1,04 ; 1,11]$} \\
LAeq: ( Prob[ Y > Normal ] ) & 0,112 & 0,008 & 0,000 & 1,12 & {$[1,10 ; 1,14]$} \\
\hline
\end{tabular}

Nota: Valor-p = 0,009 (Proporcionalidade das chances); e $\mathrm{R}^{2}=10,4 \%$; Acurácia $=60,9 \%$.

Figura 17 - Calibração do índice $L_{\text {Aeq }}$ para espaços urbanos abertos do município de Belo Horizonte Probabilidades preditas para a percepção do volume sonoro

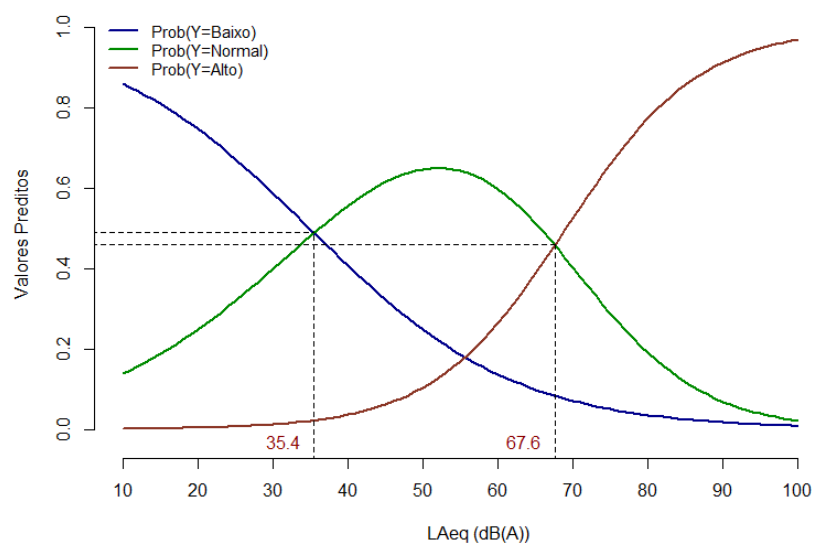

Tabela 5 - Calibração do $L_{\text {Aeq }}$ com relação à percepção do volume sonoro

\begin{tabular}{c|c}
\hline Percepção do volume sonoro & $\mathbf{L}_{\text {Aeq }}, \mathbf{e m ~ d B}(\mathbf{A})$ \\
\hline Baixo & $<35$ \\
Normal & $36 \mathrm{a} 67$ \\
Alto & $>68$ \\
\hline
\end{tabular}




\section{Calibração do descritor sonoro $L_{\text {Aeq }}$ com relação às faixas de avaliação de conforto acústico}

A Tabela 6 apresenta o ajuste da regressão logística, com vistas a analisar as relações entre o $\mathrm{L}_{\text {Aeq }}$ e a avaliação do conforto acústico.

Avaliando o ajuste da regressão na Tabela 4, podese verificar que a cada unidade acrescida ao índice $\mathrm{L}_{\text {Aeq }}$ a chance de a avaliação do conforto acústico por parte dos pedestres ser classificada na categoria "Normal" diminui em 0,92 [0,90; 0,93] vez. $\mathrm{O}$ índice $\mathrm{L}_{\text {Aeq }}$ foi capaz de explicar $8,83 \%$ das ocorrências de avaliação subjetiva do conforto acústico, sendo capaz de predizer $63,7 \%$ de respostas corretas. Pelo teste de HosmerLemeshow o modelo está adequado (valor$\mathrm{p}=0,108)$.

A Figura 18 apresenta a calibração do índice $\mathrm{L}_{\text {Aeq }}$ para espaços urbanos abertos do município de Belo Horizonte, apresentando as probabilidades preditas para a avaliação de conforto acústico com relação aos valores do índice $\mathrm{L}_{\text {Aeq }}$.

Na Figura 18 pode-se verificar que, considerando como ponto de corte a probabilidade de 0,5 (50\%), quando o valor do índice $\mathrm{L}_{\text {Aeq }}$ for menor que 68 $\mathrm{dB}(\mathrm{A})$, o conforto acústico será avaliado como "Confortável". Se o valor do índice $\mathrm{L}_{\mathrm{Aeq}}$ for maior que $68 \mathrm{~dB}(\mathrm{~A})$, o conforto acústico será avaliado pelos pedestres como "Desconfortável".

Nota-se pela análise das Tabelas 5 e 7 que houve bastante semelhança entre o limite a partir do qual os entrevistados percebem o volume sonoro como "Alto" e o limite a partir do qual os entrevistados se sentem "Desconfortáveis", o que demonstra a coerência entre as respostas dos entrevistados. Dessa maneira, quando o valor do índice $\mathrm{L}_{\mathrm{Aeq}}$ é menor que $67 \mathrm{~dB}(\mathrm{~A})$, os indivíduos percebem o volume sonoro como "Normal" e se sentem "Confortáveis", e a partir deste limite os indivíduos percebem o volume sonoro como "Alto" e se sentem "Desconfortáveis" com relação ao ambiente sonoro.

Tabela 6 - Efeito do $\mathrm{L}_{\text {Aeq }}$ sobre a avaliação de conforto acústico

\begin{tabular}{c|c|c|c|c|c}
\hline Modelo & $\boldsymbol{\beta}$ & E.P.( $\boldsymbol{\beta})$ & valor-p & O.R. & I.C. - 95\% \\
\hline LAeq & $-0,088$ & 0,008 & 0,000 & 0,92 & {$[0,90 ; 0,93]$} \\
\hline
\end{tabular}

Nota: Valor-p $=0,108$ (Hosmer-Lemeshow); e $\mathrm{R}^{2}=8,83 \%$; Acurácia $=63,7 \%$.

Figura 18 - Calibração do índice $L_{\text {Aeq }}$ para espaços urbanos abertos do município de Belo Horizonte Probabilidades preditas para a avaliação de conforto acústico

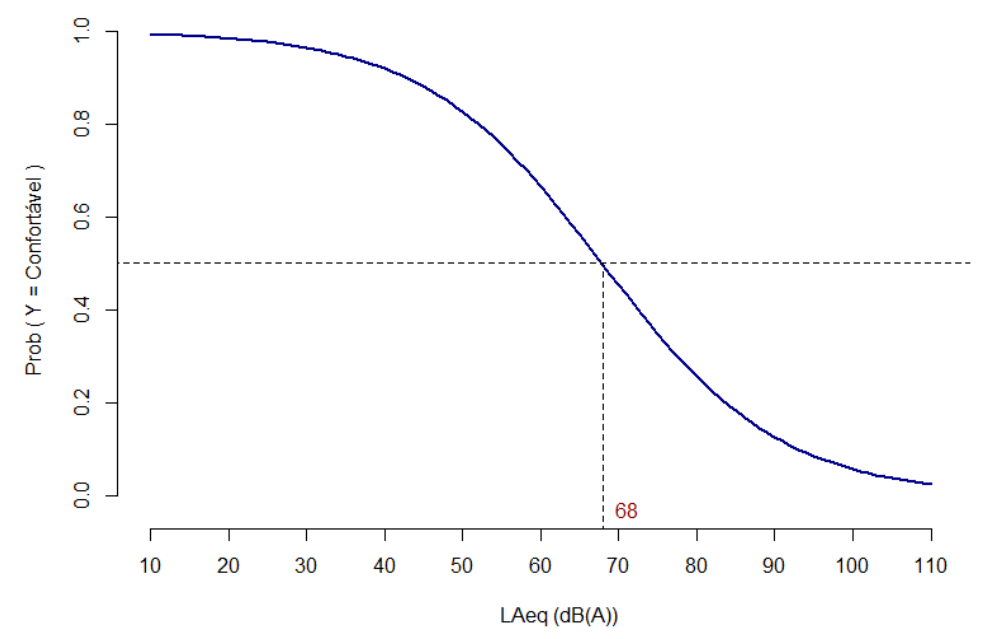

Tabela 7 - Calibração do $L_{\text {Aeq }}$ com relação à avaliação do conforto acústico

\begin{tabular}{c|c}
\hline Percepção do volume sonoro & $\mathbf{L}_{\text {Aeq }}$, em dB(A) \\
\hline Confortável & $<67$ \\
Desconfortável & $>68$ \\
\hline
\end{tabular}

20 Hirashima, S. Q. da S.; Assis, E. S. de. 


\section{Conclusões e considerações finais}

O presente artigo teve como objetivo estudar a percepção sonora e a avaliação de conforto acústico de usuários de espaços urbanos abertos do município de Belo Horizonte, MG. Os resultados demonstram que, sob as mesmas condições acústicas, tanto no que diz respeito à percepção do volume sonoro quanto à avaliação de conforto acústico, os indivíduos tendem a ser mais tolerantes na praça que possui a melhor ambiência e as melhores condições de conforto térmico (HIRASHIMA, 2014); e tendem também a ser mais tolerantes no inverno, época (estação do ano) em que as condições térmicas estão, na maior parte do tempo, dentro da zona de conforto térmico (HIRASHIMA, 2014). Ao se comparar as respostas dos usuários com relação à percepção do volume sonoro com as respostas com relação à avaliação de conforto acústico, considerando as mesmas faixas do descritor sonoro $\mathrm{L}_{\text {Aeq }}$, nota-se que os usuários, na maioria das vezes, são mais tolerantes com relação à avaliação de conforto acústico do que com relação à percepção de volume sonoro. Com relação à percepção do volume sonoro, os usuários dos espaços urbanos em Belo Horizonte consideram o volume sonoro: Baixo, quando o $\mathrm{L}_{\mathrm{Aeq}}<35 \mathrm{~dB}(\mathrm{~A})$; Normal, quando o $\mathrm{L}_{\text {Aeq }}$ está entre 36 e $67 \mathrm{~dB}(\mathrm{~A})$; Alto, quando $\mathrm{L}_{\text {Aeq }}$ $>68 \mathrm{~dB}(\mathrm{~A})$. Considerando a avaliação do conforto acústico, os usuários dos espaços urbanos em Belo Horizonte consideram o volume sonoro: Confortável, quando o $\mathrm{L}_{\text {Aeq }}<67 \mathrm{~dB}(\mathrm{~A})$; e Desconfortável, quando o $\mathrm{L}_{\mathrm{Aeq}}>68 \mathrm{~dB}(\mathrm{~A})$. Houve bastante semelhança entre o limite a partir do qual os entrevistados percebem o volume sonoro como "Alto" e o limite a partir do qual os entrevistados se sentem "Desconfortáveis", o que demonstra a coerência entre as respostas dos entrevistados. Ressalta-se que este valor de $67 \mathrm{~dB}(\mathrm{~A})$ representa níveis sonoros superiores ao limite diurno estabelecido para conforto acústico em ambientes externos pela NBR 10151, para área mista, com vocação comercial e administrativa, que é de 60 $\mathrm{dB}(\mathrm{A})$. Entretanto, o objetivo deste estudo não é a comparação das faixas delimitadas com os limites estabelecidos pela legislação existente. A legislação existente embasa-se em outros parâmetros além das questões subjetivas de percepção sonora e de conforto acústico. O objetivo do presente estudo é fornecer subsídios para o planejamento e para o projeto urbanos, uma vez que o conhecimento das faixas de percepção sonora e de conforto acústico são fatores que podem ser utilizados com o objetivo de embasar soluções que visem proporcionar uma maior sensação de conforto acústico nesses espaços. A identificação das condições em que a população é mais tolerante às condições acústicas existentes se mostra um importante instrumento para o projeto e planejamento urbanos. Portanto, os resultados do presente estudo podem ser de grande importância para a tomada de decisão em projetos urbanísticos, principalmente em situações em que não há possibilidades de grandes reduções nos níveis de pressão sonora, ou possibilidades de controle do ruído nas fontes.

\section{Referências}

AGRESTI, A. Categorical Data Analysis. New York: Wiley, 2002.

\section{ASSOCIAÇÃO BRASILEIRA DE NORMAS}

TÉCNICAS. NBR 10151: acústica: avaliação do ruído em áreas habitadas, visando o conforto da comunidade: procedimento. Rio de Janeiro, 2000

BANGJUN, Z.; LILI, S.; GUOQUING, D. The Influence of the Visibility of the Source on the Subjective Annoyance Due to Its Noise. Applied Acoustics, v. 64, p. 1205-1215, 2003.

BOTTELDOOREN, D.; DE COENSEL, B.; DE MUER, T. The Temporal Structure of Urban Soundscapes. Journal of Sound and Vibration, v. 292, p.105-123, 2006.

FIELDS, J. M. et al. Standardized GeneralPurpose Noise Reaction Questions for Community Noise Surveys: research and a recommendation. Journal of Sound and Vibration, v. 242, n. 4, p. 641-679, 2001.

FUCHS, G. L. Subjective Evaluation of Transport Noise in Latin America. Journal of Sound and Vibration, v. 43, n. 2, p. 387-394, 1975.

HIRASHIMA, S. Q. S. Percepção Sonora e Térmica e Avaliação de Conforto em Espaços Urbanos Abertos do Município de Belo Horizonte - MG, Brasil. Sãof Paulo, 2014. 246 f. Tese (Doutorado em Engenharia Civil) Faculdade de Arquitetura e Urbanismo, Universidade de São Paulo, São Paulo, 2014.

HOSMER, D. W.; LEMESHOW, S. Applied Logistic Regression. New York: Wiley, 2000. INTERNATIONAL ORGANIZATION FOR STANDARDIZATION. ISO 1996: acoustics: description, measurement and assessment of environmental noise: part 1: basic quantities and assessment procedures. Geneve, 2003a.

INTERNATIONAL ORGANIZATION FOR STANDARDIZATION. ISO 1996: acoustics: description, measurement and assessment of environmental noise: part 2: determination of sound pressure levels. Geneve, 2007. 
INTERNATIONAL ORGANIZATION FOR STANDARDIZATION. ISO/TS 15666: acoustics: assessment of noise annoyance by means of social and socio-acoustic surveys. Genève, 2003b.

LAMURE, C. Human Response to Traffic Noise. Journal of Sound and Vibration, v. 43, n. 2, p. $377-385,1975$

KANG, J.; YANG, W.; ZHANG, M. Sound Environment and Acoustic Comfort in Urban Spaces. In: DESIGNING Open Spaces in the Urban Environment: a bioclimatic approach. Rediscovering the urban realm and open spaces - RUROS, p. 32-36, 2004.

NAGELKERKE, N. J. D. A Note on a General Definition of the Coefficient of Determination. Biometrika, v. 78, p. 691-692, 1991.

PEREIRA, M. Percepção Sonora no Espaço Público: indicadores de tolerância ao ruído na cidade do Rio de Janeiro. In: ENCONTRO NACIONAL DE CONFORTO NO AMBIENTE CONSTRUÍDO, Curitiba, 2003. Anais... Curitiba: ENTAC, 2003.

PETERSON, B. L.; HANRREL, F. E. Partial Proportional Odds Models for Ordinal Response Variables. Applied Statistic, v. 39, n. 2, p. $205-$ 217, 1990.

PHAN, H. Y. T. et al. Community Responses to Road Traffic Noise in Hanoi and Ho Chi Minh City. Applied Acoustics, v. 71, p. 107-114, 2010.
RAIMBAULT, M.; LAVANDIER, C.; BÉRENGIER, M. Ambient Sound Assessment of Urban Environments: fields studies in two French cities. Applied Acoustics, v. 64, p. 1241-1256, 2003.

SAADU, A. A. et al. Community Attitudinal Noise Survey and Analysis of Eight Nigerian Cities. Applied Acoustics, v. 49, n. 1, p. 49-69, 1996.

VIOLLON, S.; LAVANDIER, C.; DRAKE, C. Influence of Visual Setting on Sound Ratings in an Urban Environment. Applied Acoustics, v. 63, p. 493-511, 2002.

YANG, W.; KANG, J. Acoustic Comfort Evaluation in Urban Open Public Spaces. Applied Acoustics, v. 66, p. 211-229, 2005.

WORLD HEALTH ORGANIZATION. Guidelines for Community Noise. 1999. Disponível em: <http://whqlibdoc.who.int/hq/1999/a68672.pdf>. Acesso em: 31 mar. 2011.

\section{Agradecimentos}

As autoras agradecem ao Conselho Nacional de Desenvolvimento Científico e Tecnológico (CNPq) a concessão de bolsa na modalidade Doutorado Sanduíche no Exterior (SWE), por meio do Programa Ciências Sem Fronteiras, para a primeira autora. $\mathrm{O}$ doutorado sanduíche foi realizado na University of Kent, Inglaterra, em 2014, contribuindo sobremaneira para a pesquisa, principalmente na análise e no tratamento dos dados coletados.

Simone Queiroz da Silveira Hirashima

Departamento de Engenharia Civil | Centro Federal de Educação Tecnológica de Minas Gerais | Av. Amazonas, 7675, Nova Gameleira | Belo Horizonte, MG - Brasil | CEP 30510-000 | Tel.: +55 (31) 3319-6810 | E-mail: simoneqsh@civil.cefetmg.br

Eleonora Sad de Assis

Departamento de Tecnologia da Arquitetura e do Urbanismo | Universidade Federal de Minas Gerais | Rua Paraíba, 697, Funcionários | Belo Horizonte - MG - Brasil | CEP 30130-140 | Tel.: (31) 3409-8873 | E-mail: eleonorasad@yahoo.com.br

\section{Revista Ambiente Construído}

Associação Nacional de Tecnologia do Ambiente Construído

Av. Osvaldo Aranha, $99-3^{\circ}$ andar, Centro

Porto Alegre - RS - Brasil

CEP 90035-190

Telefone: +55 (51) 3308-4084

Fax: +55 (51) 3308-4054

www.seer.ufrgs.br/ambienteconstruido

E-mail: ambienteconstruido@ufrgs.br

22 Hirashima, S. Q. da S.; Assis, E. S. de. 